\title{
BALLISTIC EFFECTIVENESS OF Zr-CONTAINING COMPOSITE SOLID PROPELLANTS AS A FUNCTION OF BINDER NATURE AND MASS FRACTION
}

\author{
D. B. Lempert ${ }^{1}$, M. Brambilla ${ }^{2}$, and L. T. DeLuca ${ }^{2}$ \\ ${ }^{1}$ Institute of Problems of Chemical Physics \\ Russian Academy of Sciences \\ 1 Av. Acad. Semenov, Chernogolovka 142432, Russia \\ ${ }^{2}$ Aerospace Engineering Department, Politecnico di Milano, SPLab \\ 34 Via La Masa, Milan 20156, Italy
}

This paper considers the effects of binder mass fraction on the properties of energetic formulations based on zirconium and zirconium hydride. These ingredients, replacing aluminum in solid rocket motors with low vehicle performance coefficient, may increase the propellant ballistic effectiveness, thanks to the resulting higher density and notwithstanding their lower specific impulse. The propellant ballistic effectiveness is estimated via the vehicle velocity achieved using the propellant under analysis in a real vehicle. For each specific mission, the binder content can be varied to provide the optimal relationship between energetic and physical-mechanical properties, that is, one may sacrifice energy in favor of rheological and physicomechanical properties (increasing binder mass fraction), or vice versa.

\section{NOMENCLATURE}

\section{Symbols}

$F \quad V / M_{\text {fin }}$, vehicle performance coefficient

$g_{0} \quad$ Reference gravity acceleration

$I_{\text {ef }}$ Effective specific impulse (see Eq. (1))

$I_{\mathrm{sp}} \quad$ Specific impulse 
$M \quad$ Mass

$T$ Temperature

$V \quad$ Volume

$\alpha \quad$ Oxygen excess coefficient

$\Delta H_{f}^{\circ}$ Enthalpy of formation

$\Delta v \quad$ Velocity increment

$\rho \quad$ Density

\section{Abbreviations}

$\mathrm{AB}$ Active binder

ADN Ammonium dinitramide

Al Aluminum

AP Ammonium perchlorate

HCB Hydrocarbon binder

HMX Cyclotetramethylene-tetranitramine

$\mathrm{Zr} \quad$ Zirconium

$\mathrm{ZrH}_{2}$ Zirconium hydride

2P Two-phase flow

\section{Subscripts}

c Combustion (temperature)

fin Final (mass)

ln Initial launch (mass)

pr Propellant (mass)

ref Reference (baseline)

\section{INTRODUCTION}

Composite solid propellants are used in both space and defense applications. The simplest formulation consists of an inorganic solid oxidizer entrapped in a polymeric binder that also works as a combustible. To increase solid propellants performance and stability, metal powders (such as $\mathrm{Al}, \mathrm{B}$, and $\mathrm{Be}$ ) are added as high energy density fuel. Among these metals, the most known and used is Aluminum, because it is relatively low-cost, accessible, and widespread. However, metals hardly burn because of difficult ignition, not complete oxidation reaction, and uncertain combustion feed, both in homogeneous and heterogeneous phase [1]. The worst mishaps are connected with the two-phase expansion in supersonic nozzles and gravimetric specific impulse $\left(I_{\mathrm{sp}}\right)$ losses. 
Mechanical properties (strain and elasticity) are an essential requirement to certificate a propellant for flight missions. One of the most influential parameters is the volume percentage (with respect to the total compound) of the polymeric binder. If other characteristics are the same, mechanical properties are better, the higher is the binder volume percentage (typically, in the range $16 \%$ to $30 \%$ ). Additionally, it is the binder percentage that especially affects manufacturing: it is very difficult, if not impossible, to make a propellant without enough binder; on the other hand, an excessive binder content depresses specific impulse.

In this paper, the concept of "ballistic effectiveness" is introduced to identify the propellant formulation that allows a missile to reach the highest velocity. So, the higher is the ballistic effectiveness, the higher is the vehicle velocity as shown by Eq. (1) (to be discussed later).

The ballistic effectiveness of composite solid propellants depends on many factors, such as specific impulse $\left(I_{\mathrm{sp}}\right)$, density $(\rho)$, power $n$ in Vieille's combustion law $r_{b}=a_{b} p^{n}$, and combustion temperature $\left(T_{c}\right)$. Especially density and $I_{\mathrm{sp}}$ play a considerable role in ballistic effectiveness, although the density value does not enter directly in the rocket velocity increment expression [2]. The effect of the burning rate exponent $n$ is not direct: due to poor stability of the combustor/nozzle coupling, high values of the exponent $n$ imply large pressure fluctuations. If the structure has to support higher pressure, it has to be more massive and so the ratio $M_{\mathrm{ln}} / M_{\text {fin }}$ decreases and the rocket velocity increment decreases too. For this reason, the exponent $n$ of the burning rate also affects ballistic effectiveness.

Nowadays, the most successful propellants are based on aluminum, binder, and oxidizer. But in rocket motors with comparatively low performance coefficient, namely, if $F=V / M_{\text {fin }}<1.5 \mathrm{l} / \mathrm{kg}\left(V=\right.$ propellant volume, $M_{\text {fin }}=$ final vehicle mass with no propellant), using zirconium ( $\mathrm{Zr}$ ) or zirconium hydride $\left(\mathrm{ZrH}_{2}\right)$ instead of aluminum may increase the ballistic effectiveness because of the higher propellant density in spite of its lower specific impulse [3].

Usually, the binder percentage is fixed at $20 \%$ (vol.) and the maximal ballistic effectiveness of formulations with zirconium or its hydride is achieved at $\mathrm{Zr}$ content $35 \%-45 \%$ that is considerably higher than the optimal content of $\mathrm{Al}(20 \%-22 \%)$ in Al-containing formulations. Using $\mathrm{Zr}$ or $\mathrm{ZrH}_{2}$ ensures best ballistic parameters if an active binder is used. Notice that formulations with $\mathrm{ZrH}_{2}$ are practically equivalent to formulations with $\mathrm{Zr}$, even if the hydride works better in formulations with oxygen-rich oxidizers and active binders (AB).

This paper considers the effects of binder mass fraction in formulations with $\mathrm{Zr}$ and $\mathrm{ZrH}_{2}$. Different kinds of oxidizers - Ammonium Perchlorate (AP), Ammonium Dinitramide (ADN), and Cyclotetramethylene-tetranitroamine (HMX) - and two kinds of binder, Hydrocarbon Binder (HCB) and AB, have been investigated. 
It is shown that the effective impulse, $I_{\mathrm{ef}}$, is appreciably less sensitive to binder mass fraction growth if an $\mathrm{AB}$ is used, so that one may increase the volume fraction of $\mathrm{AB}$ with little loss in $I_{\mathrm{ef}}$. On the contrary, compositions with HCB are more affected and so less effective with binder percent higher than $20 \%$ (vol.) that is the minimal value in order to obtain the necessary physicalmechanical properties and rheology.

In compositions with $\mathrm{Zr}$ or $\mathrm{ZrH}_{2}$, the maximal $I_{\mathrm{ef}}$ values are achieved at rather high $\mathrm{Zr}$ content $(37 \%-46 \%)$. In case of $\mathrm{AB}$, the binder mass fraction can be increased up to $30 \%$, especially if the oxidizer has a small oxygen excess coefficient, $\alpha$, (e.g., HMX). If the $V / M_{\text {fin }}$ value increases, the effectiveness of this replacement falls, and in this case, the role of oxidizer $\alpha$ becomes more important — the higher it is, the less, consequently, the replacement is and effectiveness falls.

When creating new composite solid propellants based on $\mathrm{Zr}$ or $\mathrm{ZrH}_{2}$, one can choose between compositions characterized by maximum effective impulse, $I_{\text {ef }}$ (with minimum binder content that is about $20 \%$ (vol.) and, consequently, worse properties), or maximum physicomechanical properties but not so high effectiveness.

In companion experimental activities [4], solid propellant formulations containing up to $40 \% \mathrm{Zr}$ were found to burn stable over a range of pressure from 20 to $80 \mathrm{~atm}$. Using $\mathrm{Zr}$, it was possible to obtain burning rates and burning rate exponents close to the values typical of compositions based on Al. But a strong dependence of the burning rate on the size of metal particles was observed for $\mathrm{Zr}$ formulations. This allows obtaining burning rates considerably higher than for similar Al-based compositions, without using ultradispersed metal.

For Zr-based compositions, burning rate and combustion laws can easily be modified by varying the component dispersion, the ratio of $\mathrm{Al}$ to $\mathrm{Zr}$ content, and by resorting to catalysts.

The cost of components and, consequently, of the whole propellant is very important and all pro et cons have to be estimated. It is remarked that the high zirconium price is known (about 50 times more expensive than $\mathrm{Al}$ ) but it is all the same investigated because there are tasks that have to be reached whatever the price is.

Moreover, it is also impossible to estimate the whole mission cost precisely, because there are not enough data yet and also, the topic of this paper is scientific and not economical. It is necessary to seek for applications in which the benefits of the material would outweigh the associated costs. Surely, for each kind of rocket systems, the optimum formulation may be different.

All thermochemical calculations were carried out using the software package Terra [5] and considering an adiabatic isentropic process with $P_{c}: P_{a}=40: 1$ (according to the Russian standard). Pressure oscillations and other nonthermochemical issues are out of the scope of this paper. 


\section{METHOD OF INVESTIGATION}

In assessing ballistic effectiveness, the main role is played by specific impulse and density, even if density does not appear directly in the Tsiolkovsky's expression of the rocket velocity increment:

$$
\Delta v=g_{0} I_{\mathrm{sp}} \ln \left(\frac{M_{\mathrm{ln}}}{M_{\mathrm{fin}}}\right)
$$

where $M_{\mathrm{ln}}$ is the initial launch mass; $M_{\mathrm{fin}}=M_{\mathrm{ln}}-M_{\mathrm{pr}}$ is the final rocket mass $=$ initial launch mass - propellant mass; $M_{\mathrm{pr}}=\rho V$ is the (propellant density $) \times($ propellant volume $)$; and $g_{0}$ is the reference gravity acceleration. Therefore,

$$
\Delta v=g_{0} I_{\mathrm{sp}} \ln \left(1+\frac{\rho V}{M_{\mathrm{fin}}}\right) .
$$

For a given rocket performance parameter (i.e., for a given $F=V / M_{\text {fin }}$ ), if the propellant density steps up, $M_{\mathrm{ln}}$ value increases too and, consequently, at the same $I_{\mathrm{sp}}, \Delta v$ increases. So, if we have two different propellants (the first characterized by $I_{\mathrm{sp} 1}$ and $\rho_{1}$, and the other one by $I_{\mathrm{sp} 2}$ and $\rho_{2}$, both at the same $\left.V / M_{\text {fin }}\right)$ the propellant with higher $\rho$-value provides higher $\Delta v$ if $I_{\mathrm{sp} 1}=I_{\mathrm{sp} 2}$.

The less is the mass fraction taken by the propellant in $M_{\mathrm{ln}}$, the higher is the propellant density input to the resulting $\Delta v$ value: the role of density increases for rockets with high $F=V / M_{\text {fin }}$ ratio, that is for the lower stages of multiple stages missiles or missiles with relatively high $F$ ratio.

In this paper, it is discussed how the binder mass fraction can change the ballistic effectiveness of Zr-containing formulations. Three oxidizers [6, 7], with different oxygen excess coefficient $(\alpha)$ and formation enthalpy $\left(\Delta H_{f}^{\circ}\right)$, and two binders, HCB and AB, are analyzed. Relevant data are reported in Table 1.

Table 1 Energetic properties of examined ingredients

\begin{tabular}{lllrrl}
\hline Purpose & \multicolumn{1}{c}{ Ingredient } & \multicolumn{1}{c}{ Formula } & $\Delta H_{f}, \mathrm{~kJ} / \mathrm{kg}$ & $\rho, \mathrm{g} / \mathrm{cm}^{3}$ & $\alpha^{*}$ \\
\hline \multirow{2}{*}{ Oxidizer } & $\mathrm{AP}$ & $\mathrm{NH}_{4} \mathrm{ClO}_{4}$ & -2478 & 1.95 & 2.70 \\
& $\mathrm{ADN}$ & $\mathrm{NH}_{4} \mathrm{~N}\left(\mathrm{NO}_{2}\right)_{2}$ & -1129 & 1.82 & 2.00 \\
& $\mathrm{HMX}$ & $\mathrm{C}_{4} \mathrm{H}_{8} \mathrm{~N}_{4}\left(\mathrm{NO}_{2}\right)_{4}$ & 322 & 1.92 & 0.67 \\
\hline \multirow{2}{*}{ Binder } & $\mathrm{HCB}$ & $\mathrm{C}_{73.17} \mathrm{H}_{120.9}$ & -393 & 0.92 & 0 \\
& $\mathrm{AB}$ & $\mathrm{C}_{18.96} \mathrm{H}_{34.64} \mathrm{~N}_{19.16} \mathrm{O}_{29.32}$ & -757 & 1.49 & 0.53 \\
\hline \multirow{2}{*}{ Energetic } & Aluminum & $\mathrm{Al}$ & 0 & 2.70 & 0 \\
\multirow{2}{*}{ compound } & Zirconium & $\mathrm{Zr}$ & 0 & 6.49 & 0 \\
& Zirconium hydride & $\mathrm{ZrH}_{2}$ & -1902 & 5.61 & 0 \\
\hline
\end{tabular}

${ }^{*} \alpha=\mathrm{O} /[2 \mathrm{C}+0.5(\mathrm{H}-\mathrm{Cl})]$. 
The formulation taken as baseline is $\mathrm{Al}(20 \%$ (mass.)) + HCB (20\%(vol.)) and the rest being AP. This formulation is characterized by $I_{\mathrm{sp}}=251 \mathrm{~s}$, density $\rho=1.85 \mathrm{~g} / \mathrm{cm}^{3}$, and $T_{c}=3610 \mathrm{~K}$. This baseline was chosen because it is one of the most commonly used propellant formulation, well known, accessible, and easy to produce. If the rocket under consideration is loaded with this basic composition and this composition is replaced with another one with specific impulse value $I_{\mathrm{sp} 2}$ and density $\rho_{2}$, it is easy to calculate the so-called effectiveness impulse $\left(I_{\mathrm{ef}}\right)$ of the second composition if used in a rocket vehicle with the same ratio $V / M_{\text {fin }}$. It means that the velocity increment $\Delta v$ of the vehicle with this value of $V / M_{\text {fin }}$ would be equal by using either the second composition $\left(I_{\mathrm{sp} 2}\right.$ and density $\rho_{2}$ ) or a composition with density $\rho=1.85 \mathrm{~g} / \mathrm{cm}^{3}$ and $I_{\mathrm{sp}}=I_{\text {ef }}$. Thus, if $I_{\text {ef }}$ of the second composition is higher than $251 \mathrm{~s}$, the replacement will augment the velocity increment $\Delta v$ and will be effective. The comparison of different formulations effectiveness for missiles with different volume-mass parameters, has been developed with several $V / M_{\text {fin }}$ values (from 0.27 to $4.86 \mathrm{l} / \mathrm{kg}$ ). That is equal to $M_{\text {ln }} / M_{\text {fin }}=1+1.85 V / M_{\text {fin }}$ from 1.5 to 10 , if $\rho=1.85 \mathrm{~g} / \mathrm{cm}^{3}$. In this paper, only few of them are discussed, from 0.27 to $1.35 \mathrm{l} / \mathrm{kg}$ with step $\Delta=0.27 \mathrm{l} / \mathrm{kg}$, because after that value, Zr-based formulations effectiveness decreases and cons are more than pros, so the replacement is not effective.

At each $V / M_{\text {fin }}$, the vehicle velocity increment $\Delta v$ is calculated as

$$
\begin{array}{rlr}
\Delta v_{\text {ref }} & =g_{0} I_{\text {sp ref }} \ln \left(1+\frac{\rho_{\text {ref }} V}{M_{\text {fin }}}\right)=g_{0} \cdot 251 \ln \left(1+\frac{1.85 V}{M_{\text {fin }}}\right) & \text { baseline; } \\
\Delta v_{i}=g_{0} I_{\text {sp }} \ln \left(1+\frac{\rho_{i} V}{M_{\text {fin }}}\right) & \text { other cases. }
\end{array}
$$

A new parameter, the effective specific impulse $I_{\mathrm{ef}}$, can be calculated as follows:

$$
\begin{gathered}
\Delta v_{\text {ref }}=\Delta v_{i} \text { implying } g_{0} \cdot 251 \ln \left(1+\frac{1.85 V}{M_{\text {fin }}}\right)=g_{0} I_{\text {ef }} \ln \left(1+\frac{\rho_{i} V}{M_{\text {fin }}}\right) ; \\
I_{\text {ef }}=\frac{251 \ln \left(1+1.85 V / M_{\text {fin }}\right)}{\ln \left(1+\rho_{i} V / M_{\text {fin }}\right)} .
\end{gathered}
$$

The physical meaning of $I_{\text {ef }}$ is the following: the $i$ th composition, characterized by $I_{\text {ef } i}$ and $\rho_{i}$, used in a vehicle with a given $V / M_{\text {fin }}$ ratio achieves the same $\Delta v$ value as any composition with $\rho=1.85 \mathrm{~g} / \mathrm{cm}^{3}$ and $I_{\mathrm{sp}}=I_{\mathrm{ef}} i$.

If $I_{\mathrm{ef} i}>I_{\mathrm{sp} \mathrm{ref}}$ (that is, $\Delta I_{\mathrm{ef} i}=I_{\mathrm{ef} i}-I_{\mathrm{sp} \mathrm{ref}}=I_{\mathrm{ef} i}-251>0$ ), the investigated formulation is more effective than the basic one. Otherwise, if $I_{\mathrm{ef}}<I_{\mathrm{sp} \text { ref }}$, the formulation under investigation is less effective than the basic composition.

The three oxidizers were chosen because they are produced in industry, are less hygroscopic than others, have rather high thermal stability and satisfactory impact sensitivity. Moreover, they have different values of density, enthalpy of formation, and $\alpha$ and, so, in this way, it is possible to summarize many oxidizers. 


\subsection{Two-Phase Flow Losses}

When a condensed phase appears among the combustion products, some heat is carried away from the nozzle with these liquid/solid particles; and they are superheated in comparison with gas phase, because thermal equilibrium between gas and solid phase cannot be established during the short time taken by combustion products to expand through the nozzle. The thermodynamic code "Terra," as well as similar 1-phase programs, assumes that the temperature of the gaseous phase is equal to the temperature of the solid phase (sure, at the same cross section); therefore, the actual value of $I_{\mathrm{sp}}$ is a bit lower than the calculated one. This phenomenon is very difficult to be completely accounted for, since the value of $I_{\mathrm{sp}}$ losses depends on many factors (propellant mass, kind and size of motor, percent of condensed products in the combustion products, average size and size distribution of particles of condensed phase in combustion products, etc.).

In this paper, two-phase flow (2P) losses are not calculated but only the first estimation is given, to have an idea about their influence on the ballistic effectiveness.

From experimental data, it is known that increasing $\mathrm{Al}$ by $1 \%, I_{\mathrm{sp}}$ decreases by about $0.22 \%$ [8]. If condensed phase sizes and all other parameters of the motor are assumed to be the same (only thermal capacity and condensed phase percent are changed by replacing $\mathrm{Al}$ for $\mathrm{Zr}$ or $\mathrm{ZrH}_{2}$ ), one may estimate that $2 \mathrm{P}$ losses in compositions with $\mathrm{Zr}$ or $\mathrm{ZrH}_{2}$ would be lower than in compositions with Al. Relevant data and estimates are summarized in Table 2.

The two-phase effect in compositions with $\mathrm{Zr}$ or $\mathrm{ZrH}_{2}$ (for each $1 \%$ of the fuel) is about 2.7 times lower because of its smaller specific heat and less amount of condensed products. As the actual compositions with $\mathrm{Zr}$ or $\mathrm{ZrH}_{2}$ contain a higher percent of condensed oxide in combustion products than compositions with $\mathrm{Al}$, the ratio of the corresponding $2 \mathrm{P}$ losses $(2 \mathrm{P} \text { loss })_{\mathrm{Al}} /(2 \mathrm{P} \text { loss })_{\mathrm{Zr}}$ will be a bit lower than 2.7 .

Ballistic effectiveness changes considerably only in formulations with $\mathrm{Al}$ : considering $2 \mathrm{P}$ losses, formulations with medium metal content are more effective than highly metallized formulations. In Zr-containing formulations, $I_{\mathrm{ef}}$ decreases, but compositions with good effectiveness are the same as the ones without considering losses.

Table 2 Two-phase flow losses

\begin{tabular}{lcrl}
\hline & Condensed phase & \multicolumn{1}{c}{$c^{*}$} & $\Delta I_{\mathrm{sp}}$ \\
\hline $1 \% \mathrm{Al}$ & $1.88 \% \mathrm{Al}_{2} \mathrm{O}_{3}$ & $162.9 \mathrm{~J} /(\mathrm{mol} \cdot \mathrm{K})$ & $-0.22 \%$ \\
$1 \% \mathrm{Zr}$ & $1.35 \% \mathrm{ZrO}_{2}$ & $78.1 \mathrm{~J} /(\mathrm{mol} \cdot \mathrm{K})$ & $-0.078 \%$ \\
$1 \% \mathrm{ZrH}_{2}$ & $1.32 \% \mathrm{ZrO}_{2}$ & $78.1 \mathrm{~J} /(\mathrm{mol} \cdot \mathrm{K})$ & $-0.08 \%$ \\
\hline${ }^{*}$ Molar specific heat values $c$ are taken from Terra, at $T=2500 \mathrm{~K}$.
\end{tabular}




\subsection{Temperature}

Formulations containing aluminum have lower combustion temperature than formulation filled by zirconium, even though the heat of formation of $1 \mathrm{~g}$ of $\mathrm{Al}_{2} \mathrm{O}_{3}$ is about two times higher than the heat of formation of $1 \mathrm{~g}$ of $\mathrm{ZrO}_{2}$.

That is because the Zr-based formulations form two times more condensed metal oxide $\left(\mathrm{ZrO}_{2}\right)$ in combustion products than Al-based ones do in forming condensed $\mathrm{Al}_{2} \mathrm{O}_{3}$, and the specific heat capacity of condensed products is substantially lower than heat capacity of gases. Moreover, $\mathrm{ZrO}_{2}$ dissociates in less amount than $\mathrm{Al}_{2} \mathrm{O}_{3}$ and the dissociation absorbs a lot of heat (the energy needed to heat $1 \mathrm{~g}$ of $\mathrm{Al}_{2} \mathrm{O}_{3}$ from 3600 to $4000 \mathrm{~K}$ is three times higher than the energy required to heat $1 \mathrm{~g}$ of $\mathrm{ZrO}_{2}$ from 3600 to $4000 \mathrm{~K}$ ).

When the combustion temperature is higher than $3700-3800 \mathrm{~K}$, the nozzle section needs an additional thermal protection, and, consequently, the overall rocket mass increases. The more the combustion temperature is above $3700 \mathrm{~K}$, the more thermal protection is needed and this extramass causes the fall of ballistic effectiveness. This implies that if one has two propellants with the same effectiveness but the second composition features $T_{c}$ of $100 \mathrm{~K}$ lower than the first one, it is like one has two propellants with the same temperature but the second composition offers an effectiveness $1 \mathrm{~s}$ higher than the first one. Quantitatively, if a propellant has $I_{\mathrm{sp}}=I_{\mathrm{sp} 1}$ and $T_{c}>3700 \mathrm{~K}$, it would be equal to the second propellant with the same density and characterized by $T_{c}=3700 \mathrm{~K}$ but with $I_{\mathrm{sp}}=I_{\mathrm{sp} 1}-0.01\left(T_{c}-3700\right)$.

\section{DISCUSSION OF RESULTS}

In this first part, general observations about compositions are made. Even if calculations were conducted for a large number of $F=V / M_{\text {fin }}$ values, only the most interesting ones are reported. From the figures and table below, it is clear that $I_{\text {ef }}$ depends on oxidizer, binder, and metal nature as well as their amount.

If the $V / M_{\text {fin }}$ value is from 0.27 up to about $0.8 \mathrm{l} / \mathrm{kg}$ (that is, $M_{\mathrm{ln}} / M_{\text {fin }}$ between 1.5 and about 2.5 if density value $\rho$ is $1.85 \mathrm{~g} / \mathrm{cm}^{3}$ ), the formulations filled with $\mathrm{Zr}$ or its hydride are more effective than Al-based formulations. The lower is the $V / M_{\text {fin }}$ value, the higher is the gap. When $V / M_{\text {fin }}$ is between 0.8 and $1.3 \mathrm{l} / \mathrm{kg}$, the formulations containing aluminum are equal to formulations with $\mathrm{Zr}$ while for $V / M_{\text {fin }}$ higher than $1.35 \mathrm{l} / \mathrm{kg}$, Al-based formulations outgo the Zr-based ones.

If $V / M_{\text {fin }}$ is low and the composition is filled by $\mathrm{Zr}$ or $\mathrm{ZrH}_{2}$, the binder content can be increased up to $30 \%$ (and even 34\%) allowing mechanical properties to be improved. At high $V / M_{\text {fin }}$ value, it is the binder nature and, especially, the binder oxygen excess that affect the ballistic effectiveness. 


\subsection{Influence of Oxidizer on Effectiveness}

How does the oxidizer nature influence the ballistic effectiveness?

Formulations with AP. If $V / M_{\text {fin }}$ is low (under $0.8 \mathrm{l} / \mathrm{kg}$ ), $\mathrm{Zr}$ and $\mathrm{ZrH}_{2}$ are more effective than $\mathrm{Al}$, especially for $\mathrm{AB}$. In compositions with $\mathrm{AB}$, the maximum effectiveness is achieved at high $\mathrm{Zr}$ content (the advantage is bigger when $\mathrm{Zr}$ or $\mathrm{ZrH}_{2}$ content is higher) and in this case, the binder can be increased up to $30 \%$ (vol.) and more, both for $\mathrm{Zr}$ and its hydride, without losing $I_{\mathrm{ef}}$.

If binder is $\mathrm{HCB}$, the maximum effectiveness is achieved at medium $\mathrm{Zr}$ content $(43 \%-46 \%), I_{\mathrm{ef}}$ is considerably lower and by increasing binder, the effectiveness quickly falls.

If other parameters are the same, $\mathrm{Zr}$ achieves the same effectiveness than its hydride in compositions with $\mathrm{AB}$ ( $I_{\mathrm{ef}}$ is always higher than $240 \mathrm{~s}$ and binder can be increased as needed; $I_{\text {ef }}$ is even always higher than $250 \mathrm{~s}$ if $F=0.25 \mathrm{l} / \mathrm{kg}$ ) but it is better if binder is HCB and it is better if the binder content is higher.

If $V / M_{\text {fin }}$ is higher than $1 \mathrm{l} / \mathrm{kg}$, the gain decreases, especially if binder is $\mathrm{HCB}$, and binder cannot be increased without losing ballistic effectiveness.

Formulations with ADN. The advantage of $\mathrm{AB}$ is more considerable than for systems based on AP: $(\mathrm{AB}+\mathrm{ADN})$-based systems are always better than the corresponding compositions containing AP, while compositions containing $\mathrm{HCB}$ and $\mathrm{ADN}$ are worse than the AP-based ones at low $F$-values.

If the binder is $\mathrm{HCB}$, by increasing binder content, $I_{\mathrm{ef}}$ soon falls, especially with $\mathrm{ZrH}_{2}$; the slopes of $I_{\text {ef }}$ plotted at growing binder volume percentages are higher in case of $\mathrm{Zr}$, and especially $\mathrm{ZrH}_{2}$, than in case of aluminum and the gain is so little that the replacement is considered not interesting. The best results are achieved at medium $\mathrm{Zr}$ or $\mathrm{ZrH}_{2}$ content (about $37 \%-43 \%$ ). If binder is $\mathrm{AB}$, it can be increased up to $30 \%$ and more and if $V / M_{\text {fin }}$ is fixed, $I_{\text {ef }}$ does not change (e.g., if $\mathrm{Zr}=40 \%$ (vol.) and $\mathrm{AB}=30 \%$ (vol.), the gain is about $20-25 \mathrm{~s}$ at $F=0.27 \mathrm{l} / \mathrm{kg}$. By increasing $F$, the gain falls and at $F=1.35 \mathrm{l} / \mathrm{kg}$, it is only $5 \mathrm{~s}$ ). Best results are achieved at high $\mathrm{Zr}$ or $\mathrm{ZrH}_{2}$ content. Zirconium is better than $\mathrm{ZrH}_{2}$ if binder is $\mathrm{HCB}$; they are pretty equal in compositions containing $\mathrm{AB}$.

Formulations with HMX. Hydrocarbon binder looses more than AB; formulations containing $\mathrm{HCB}$ and $\mathrm{ZrH}_{2}$ are even much worse than the baseline: if binder content is more than $20 \%, I_{\text {ef }}$ is always lower than $240 \mathrm{~s}$ and, by increasing binder, $I_{\text {ef }}$ falls, especially at high $F$ value; in this case, the replacement is a failure. The formulations containing HCB (especially the ones filled with $\mathrm{ZrH}_{2}$ ) achieve bad results: $I_{\text {ef }}$ is low and, by increasing binder, effectiveness quickly falls, because all of the components have low $\alpha$ value that means they contain much more hydrogen than oxygen and maximum energetic 
potential it is no longer assured. It is necessary to use more active binders, such as $\mathrm{AB}$ with higher oxygen content. The AB-based systems have effectiveness higher than systems containing $\mathrm{Al}$ (always, if $F$ is low) both with $\mathrm{Zr}$ and $\mathrm{ZrH}_{2}$ and the best results are achieved at medium $\mathrm{Zr}$ or $\mathrm{Zr}$ hydride contents (between $37 \%$ and $43 \%$ ). The composition $37 \% \mathrm{Zr}+\mathrm{AB}+\mathrm{HMX}$ is the best, being its effectiveness always bigger than all the others (e.g., with $\mathrm{AB}=30 \%$ (vol.), $I_{\mathrm{ef}}$ is, respectively, at $F=0.27,0.54,0.81,1.08$, and $1.35 \mathrm{l} / \mathrm{kg}$, about 281, 273,268, 265, and $261 \mathrm{~s}$ ) but if $F>3 \mathrm{l} / \mathrm{kg}, \mathrm{Al}$ wins by about $3 \mathrm{~s}$.

\subsection{Influence of $F$ Coefficient on Effectiveness}

Below, there are some draft resumes concerning the relative effectiveness of formulations with $\mathrm{Zr}$ or $\mathrm{ZrH}_{2}$ compared to baseline at few values $F=V / M_{\text {fin }}$ (Fig. 1). The aim is to identify the best formulation at every $V / M_{\text {fin }}$ :

(a) $\boldsymbol{F}=\mathbf{0 . 2 7} \mathbf{l} / \mathbf{k g}$ (Fig. 1a). The highest ballistic effectiveness is achieved in case of $\mathrm{Zr}+\mathrm{AB}+\mathrm{HMX}(+27 \mathrm{~s}$ when $\mathrm{AB}=28 \%$ (vol.) and $+23.5 \mathrm{~s}$ when $\mathrm{AB}=32 \%$ (vol.), if $\mathrm{Zr}$ content is $31 \%$ ). In compositions with $\mathrm{Zr}, \mathrm{HCB}$ (curves 4 and 6 ) is better at low binder percentages, but increasing binder percentages, $\mathrm{AB}$ is better because it feels less the effects of the raising binder (curves 5 and 7 are almost horizontal). Zirconium hydride gives the highest $I_{\text {ef }}$ (always $>270 \mathrm{~s}$ ) in composition with $\mathrm{AB}$ and binder can be increased up to $28 \%-30 \%$ (in this case, the gain is, at least, $15 \mathrm{~s}$ ). All oxidizers give about the same results. There are no advantages in using $\mathrm{HCB}$ because $I_{\mathrm{ef}}$ starts decreasing as soon as binder content begins increasing.

The Al-based formulations (curves 2 and 3 ) are worse than others: $\mathrm{Al}$ $+\mathrm{HCB}$ is definitely affected by binder increasing. That is why, at low $F$, density plays an important role. Generally, in every case, considering $\mathrm{Zr}$ or $\mathrm{ZrH}_{2}$-based propellants and $\mathrm{AB}$, binder can be increased up to $30 \%$ and $I_{\text {ef }}$ is always higher than $251 \mathrm{~s}$;

(b) $\boldsymbol{F}=\mathbf{0 . 5 4} \mathbf{~ 1 /} \mathbf{k g}$ (Fig. 1b). Binder can still be increased up to $30 \%$ and $I_{\text {ef }}$ is higher than $251 \mathrm{~s}$ but $\mathrm{ZrH}_{2}$ starts loosing $I_{\mathrm{ef}}$ - the more, the bigger is $\alpha$ of the oxidizer. $I_{\mathrm{ef}}$ of $\mathrm{Al}+\mathrm{AB}+\mathrm{HMX}$ (curve 3 ) compositions starts growing;

(c) $\boldsymbol{F}=\mathbf{0 . 8 1} \mathbf{~ l} / \mathbf{k g}$ (Fig. 1c). At high binder percentage, all $I_{\text {ef }}$, except for $\mathrm{Zr}+\mathrm{AB}+\mathrm{HMX}$ (curve 8), are lower than $260 \mathrm{~s}$. Compositions containing HCB (curves 4 and 6 ) are not effective. The bigger is the oxidizer $\alpha$-value, the higher the effectiveness is; 


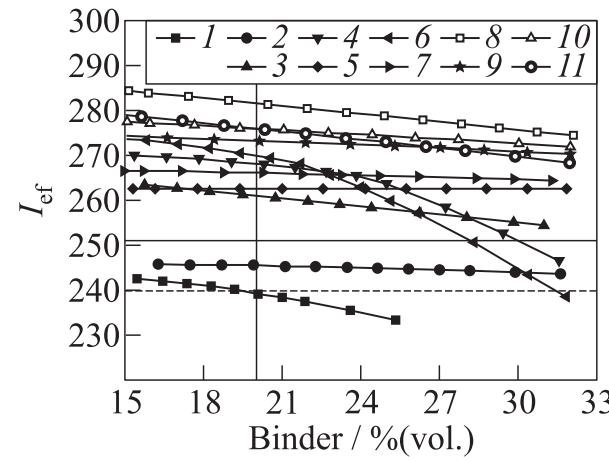

(a)

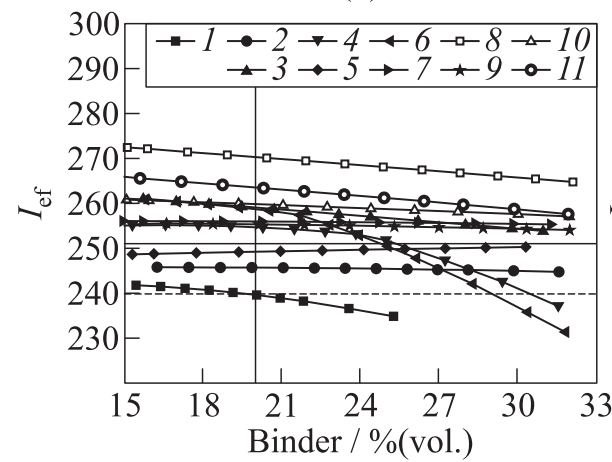

(c)

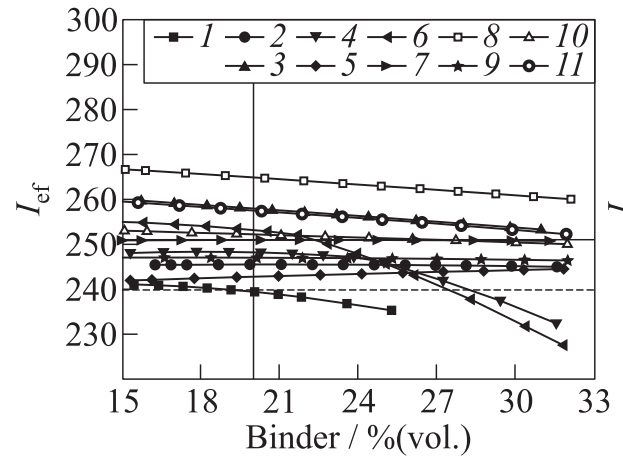

(e)

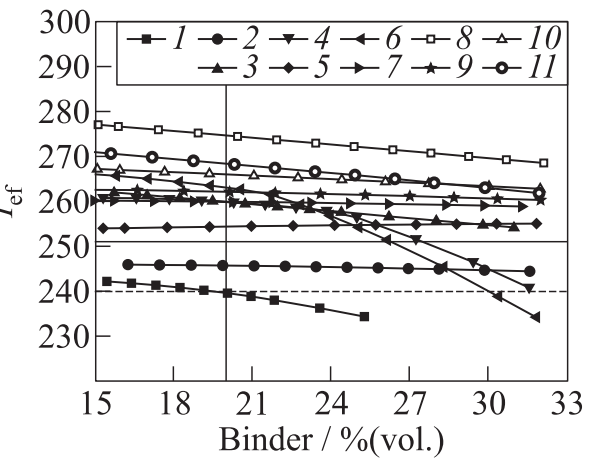

(b)

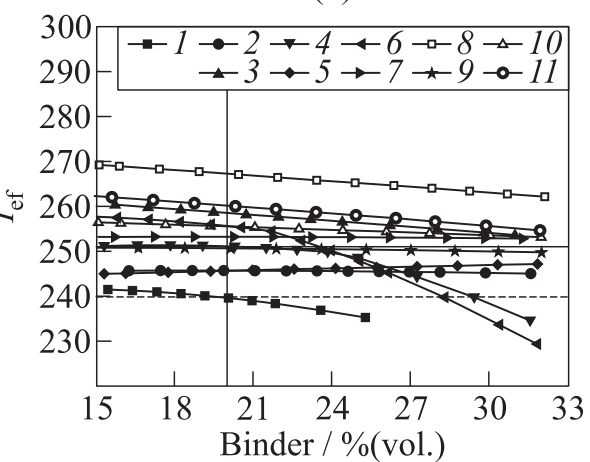

(d)

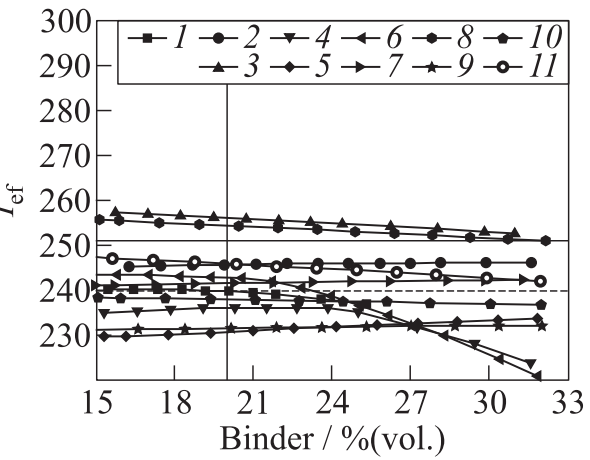

(f)

Figure 1 Binder mass fraction influence on $I_{\mathrm{ef}}$ (best formulations only): $(a) F$ $=0.27 ;(b) 0.54 ;(c) 0.81 ;(d) 1.08 ;(e) 1.35 ;$ and $(f) 4.86 ; 1$ - basic; $2-$ $16 \% \mathrm{Al}+\mathrm{AB}+\mathrm{ADN} ; 3-18 \% \mathrm{Al}+\mathrm{AB}+\mathrm{HMX} ; 4-43 \% \mathrm{Zr}+\mathrm{HCB}+\mathrm{AP} ; 5-$ $37 \% \mathrm{Zr}+\mathrm{AB}+\mathrm{AP} ; 6-43 \% \mathrm{Zr}+\mathrm{HCB}+\mathrm{ADN} ; 7-34 \% \mathrm{Zr}+\mathrm{AB}+\mathrm{ADN} ; 8-$ $31 \% \mathrm{Zr}+\mathrm{AB}+\mathrm{HMX} ; 9-49 \% \mathrm{ZrH}_{2}+\mathrm{AB}+\mathrm{AP} ; 10-49 \% \mathrm{ZrH}_{2}+\mathrm{AB}+\mathrm{ADN}$; and $11-37 \% \mathrm{ZrH}_{2}+\mathrm{AB}+\mathrm{HMX}$ 
(d) $\boldsymbol{F}=\mathbf{1 . 0 8} \mathbf{~} / \mathbf{k g}($ Fig. $1 d)$. The best results are achieved in case of low $\alpha$ oxidizers. If oxidizer is HMX (curves 3, 8, and 11) and binder is $28 \%$ (vol.), the gain is between 4 and $12 \mathrm{~s}$ (the bigger the higher metal density is). Formulations containing high $\alpha$ oxidizer (see, e.g., curves 4 and 5) start losing $I_{\mathrm{ef}}$, because they have lower $I_{\mathrm{sp}}$ in spite of higher density but density role starts decreasing;

(e) $\boldsymbol{F}=\mathbf{1 . 3 5} \mathbf{~} / \mathrm{kg}$ (Fig. 1e). The binder can be increased with a winning ( $I_{\mathrm{ef}}$ is about $260 \mathrm{~s}$ when $\mathrm{AB}$ is about $28 \%$ (vol.)) only in case of $\mathrm{HMX}+\mathrm{AB}$ filled by $\mathrm{Al}$ (curve 3), $\mathrm{Zr}$ (curve 8), or $\mathrm{ZrH}_{2}$ (curve 11) and at least $\mathrm{AB}+\mathrm{ADN}$ filled by $\mathrm{Zr}$ (curve 7 ) or $\mathrm{ZrH}_{2}$ (curve 10); in this case, $I_{\text {ef }}$ is only about $251 \mathrm{~s}$ but binder can be increased up to $28 \%$ (vol.) and more. At this $F$ value, oxidizer has more influence than metal (or hydride) on ballistic effectiveness; and

(f) $\boldsymbol{F}=4.36 \mathrm{l} / \mathrm{kg}$ (Fig. $1 f$ ). The Al-based formulations win (best results at high $\Delta H_{f}$ and low $\alpha$ ) over $\mathrm{Zr}$ and, especially, $\mathrm{ZrH}_{2}$. If binder is increased up to $28 \%$ (vol.), ( $\mathrm{Al}+\mathrm{AB}$ )-based formulations have $I_{\mathrm{ef}}$ about 254 and $247 \mathrm{~s}$, respectively, with HMX (curve 3) and ADN (curve 2); $\mathrm{Zr}+\mathrm{AB}+\mathrm{HMX}$ has $I_{\mathrm{ef}}=251 \mathrm{~s}$, while in other formulations, $I_{\mathrm{ef}}$ is lower than $243 \mathrm{~s}$. The compositions with $\mathrm{Zr}$ or its hydride and $\mathrm{HCB}+$ any oxidizer (curves 4 and 6 ) or $\mathrm{AB}+\mathrm{AP}$ (curves 5 and 9 ) are less effective than the baseline. Independently of metal or hydride content, formulation effectiveness is the worse, the bigger is the oxidizer $\alpha$-value.

\subsection{Best Formulations Analysis}

Some formulations are not interesting at any $F$-value because $I_{\text {ef }}$ is too low or $T_{c}$ is too high (see subsection 2.2): formulations containing $\mathrm{Al}$ and $\mathrm{HCB}$ have too low $I_{\text {ef }}$ and it is the same in case of formulations based on HCB, HMX, and $\mathrm{Zr}$ or $\mathrm{ZrH}_{2}$. In case of $\mathrm{ZrH}_{2}$ and $\mathrm{HCB}$, there is a gain only if $F$ is low; otherwise, basic formulation overpowers. Some formulations, especially the ones with $\mathrm{ZrH}_{2}$, have good ballistic effectiveness without any problem related to too high temperatures.

Now, the ballistic effectiveness of the best formulations is reported. The gains of effective impulse are shown in the best cases, at different binder contents, in Table 3 .

From Table 3, it can be seen that formulations containing $\mathrm{Zr}$ or its hydride and the $\mathrm{AB}$ have a great ballistic effectiveness with any oxidizer and, in these cases, binder can be increased up to $32 \%$ (vol.) and more.

If binder percentage is fixed at $32 \%$ (vol.), if $F$ is low (let say, $0.27 \mathrm{l} / \mathrm{kg}$ ), the gain is high (from 13 to $24 \mathrm{~s}$, depending on the formulation), while if $F$ is 
Table 3 Best formulations gain at different $F$ and binder volume percentage

\begin{tabular}{|c|c|c|c|c|c|c|c|c|c|}
\hline \multicolumn{10}{|c|}{$I_{\text {ef }}(\text { gain })^{*}$} \\
\hline$F, 1 / \mathrm{kg}$ & \multicolumn{3}{|c|}{0.27} & \multicolumn{3}{|c|}{0.81} & \multicolumn{3}{|c|}{1.35} \\
\hline Binder, \%(vol.) & 22 & 24 & 26 & 22 & 24 & 26 & 22 & 24 & 26 \\
\hline $20 \mathrm{Al}+\mathrm{HCB}+\mathrm{AP}$ & & & & & -10 & & & & \\
\hline $16 \mathrm{Al}+\mathrm{AB}+\mathrm{AD}$ & $-5,5$ & $-5,7$ & $-6,1$ & $-5,3$ & $-5,4$ & $-5,6$ & $-5,3$ & $-5,3$ & $-5,4$ \\
\hline $18 \mathrm{Al}+\mathrm{AB}+\mathrm{HMX}$ & 8,7 & 7,6 & 6,5 & 7,0 & 6,1 & 5,2 & 6,1 & 5,3 & 4,5 \\
\hline $36 \mathrm{Zr}+\mathrm{HCB}+\mathrm{AP}$ & 16,1 & 14,5 & 10,5 & 3,2 & 2,3 & $-1,0$ & $-2,8$ & $-3,5$ & $-6,4$ \\
\hline $37 \mathrm{Zr}+\mathrm{AB}+\mathrm{AP}$ & 11,7 & 11,7 & 11,6 & $-1,5$ & $-1,3$ & $-1,1$ & $-7,6$ & $-7,4$ & $-7,1$ \\
\hline $43 \mathrm{Zr}+\mathrm{HCB}+\mathrm{ADN}$ & 16,7 & 12,0 & 6,8 & 6,0 & 1,9 & $-2,6$ & 0,9 & $-2,8$ & $-7,1$ \\
\hline $34 \mathrm{Zr}+\mathrm{AB}+\mathrm{ADN}$ & 14,9 & 14,6 & 14,3 & 4,9 & 4,8 & 4,7 & 0,2 & 0,1 & 0,1 \\
\hline $31 \mathrm{Zr}+\mathrm{AB}+\mathrm{HMX}$ & 29,5 & 28,3 & 27,0 & 18,5 & 17,6 & 16,6 & 13,3 & 12,5 & 11,7 \\
\hline $49 \mathrm{ZrH}_{2}+\mathrm{AB}+\mathrm{AP}$ & 21,7 & 21,3 & 20,8 & 4,1 & 4,0 & 3,8 & $-3,9$ & $-3,9$ & $-4,1$ \\
\hline $49 \mathrm{ZrH}_{2}+\mathrm{AB}+\mathrm{ADN}$ & 24,3 & 23,7 & 23,0 & 8,4 & 8,0 & 7,5 & 1,0 & 0,7 & 0,3 \\
\hline $37 \mathrm{ZrH}_{2}+\mathrm{AB}+\mathrm{HMX}$ & 23,9 & 22,7 & 21,5 & 11,7 & 10,7 & 9,8 & 5,9 & 5,1 & 4,3 \\
\hline Binder, \%(vol.) & 28 & 30 & 32 & 28 & $\overline{30}$ & 32 & 28 & 30 & $\overline{32}$ \\
\hline $16 \mathrm{Al}+\mathrm{AB}+\mathrm{ADN}$ & $-6,4$ & $-6,8$ & $-7,1$ & $-5,8$ & -6 & $-6,2$ & $-5,5$ & $-5,6$ & $-5,8$ \\
\hline $18 \mathrm{Al}+\mathrm{AB}+\mathrm{HMX}$ & 5,3 & 4,1 & 2,9 & 4,2 & 3,2 & 2,2 & 3,6 & 2,7 & 1,9 \\
\hline $36 \mathrm{Zr}+\mathrm{HCB}+\mathrm{AP}$ & 5,8 & $-3,6$ & $-5,4$ & $-5,0$ & 13,5 & $-14,7$ & $-10,1$ & $-18,2$ & $-19,1$ \\
\hline $37 \mathrm{Zr}+\mathrm{AB}+\mathrm{AP}$ & 14,0 & 13,9 & 13,8 & 0,1 & 0,2 & 0,3 & $-6,4$ & $-6,2$ & $-5,9$ \\
\hline $43 \mathrm{Zr}+\mathrm{HCB}+\mathrm{ADN}$ & 0,6 & $-5,9$ & $-12,9$ & $-8,0$ & $-13,8$ & $-20,2$ & $-12,1$ & $-17,7$ & $-23,7$ \\
\hline $34 \mathrm{Zr}+\mathrm{AB}+\mathrm{ADN}$ & 14,0 & 13,7 & 13,3 & 4,6 & 4,4 & 4,2 & 0,1 & 0,0 & $-0,1$ \\
\hline $31 \mathrm{Zr}+\mathrm{AB}+\mathrm{HMX}$ & 25,9 & 24,5 & 23,5 & 15,7 & 14,8 & 13,9 & 10,9 & 10,1 & 9,3 \\
\hline $49 \mathrm{ZrH}_{2}+\mathrm{AB}+\mathrm{AP}$ & 20,3 & 19,8 & 19,3 & 3,5 & 3,3 & 3,0 & $-4,2$ & $-4,3$ & $-4,5$ \\
\hline $49 \mathrm{ZrH}_{2}+\mathrm{AB}+\mathrm{AD}$ & 22,4 & 21,6 & 20,9 & 7,1 & 6,5 & 6,0 & 0,0 & $-0,5$ & $-0,9$ \\
\hline $37 \mathrm{ZrH}_{2}+\mathrm{AB}+\mathrm{HMX}$ & 20,2 & 19,0 & 17,7 & 8,8 & 7,8 & 6,8 & 3,4 & 2,5 & 1,6 \\
\hline
\end{tabular}

${ }^{*}$ Gain $=240-I_{\text {ef } i}=\left(\right.$ basic $\left.I_{\text {ef }}\right)-I_{\text {ef } i}$.

high (e.g., $1.35 \mathrm{l} / \mathrm{kg}$ ), every formulation containing $\mathrm{Zr}$ is worse than the baseline, except for the ones with $\mathrm{AB}$ and HMX (the gain is 9.3 and $1.6 \mathrm{~s}$ with $\mathrm{Zr}$ and $\mathrm{ZrH}_{2}$, respectively).

The formulations containing $\mathrm{Zr}$ and $\mathrm{HCB}$ (curves 4 and 6 in Fig. 1) show good performance at low $F$ and low binder percentage. For example, at $F=0.27 \mathrm{l} / \mathrm{kg}$ and binder $22 \%$ (vol.), the gain is about $16 \mathrm{~s}$ for both $\mathrm{AP}$ and $\mathrm{ADN}$; but at $F=0.81 \mathrm{l} / \mathrm{kg}$ and binder $26 \%$ (vol.), there is already no gain (AP looses $1 \mathrm{~s}$ and ADN $2.6 \mathrm{~s})$.

At high $F$ value, Al-based formulations are better than $\mathrm{Zr}$-based ones. With $\mathrm{Al}$ and $\mathrm{AB}, \mathrm{HMX}$ is better than $\mathrm{ADN}$; for example, in case of $18 \% \mathrm{Al}+\mathrm{AB}$ + HMX (curve 3), when $F=0.25 \mathrm{l} / \mathrm{kg}, \Delta I_{\mathrm{ef}}$ is between 8.7 and $2.9 \mathrm{~s}$, respectively, with binder from 22 to $32 \%$ (vol.) and these gains are lower than Zr-based formulations; when $F=1.35 \mathrm{l} / \mathrm{kg}$, the gain is between 6.1 and $1.9 \mathrm{~s}$ (they seem low but are higher than Zr-based). 
The best formulation (curve 8 in Fig. 1) is always $31 \% \mathrm{Zr}+\mathrm{AB}+\mathrm{HMX}$ that, in the worse case (that is, $F=1.45 \mathrm{l} / \mathrm{kg}$ and a binder content of $32 \%(\mathrm{vol}$.)), achieves a gain of $9.3 \mathrm{~s}$, while at $F=0.7 \mathrm{l} / \mathrm{kg}$ achieves $\Delta I_{\mathrm{ef}}$ of $29.5,28.3,27$, $25.9,24.5$, and $23.5 \mathrm{~s}$, respectively, with binder from 22 to $32 \%$ (vol.).

So, for every missile with a certain $V / M_{\text {fin }}$ value, there is a specific formulation that better fits the mission.

These results are summarized in Fig. 1. The black vertical line indicates the reference binder content $(20 \%$ (vol.)). The black horizontal line is the baseline formulation $I_{\mathrm{sp}}=251 \mathrm{~s}$ without considering $2 \mathrm{P}$ losses [remember that the basic formulation is $\mathrm{Al}(20 \%)+\mathrm{HCB}(20 \%$ (vol.)) and the rest AP] and the dashed one is $I_{\mathrm{sp}}$ for the same formulation but considering two-phase effects.

\subsubsection{Specific impulse and density}

How specific impulse and density rely on binder percentage is illustrated in Fig. 2. As said, the importance of density decreases when $F$ increases. The formulations containing $\mathrm{Al}$ (curves 1-3) have the higher $I_{\mathrm{sp}}$ but the lower density.

On the contrary, compositions containing $\mathrm{Zr}$ or $\mathrm{ZrH}_{2}$ (especially with AP as oxidizer and $\mathrm{ZrH}_{2}+\mathrm{AB}+\mathrm{ADN}$ ) have the lower $I_{\mathrm{sp}}$ but very high density (curves $5,4,9$, and 6 , respectively). These formulations are better when $F$ is

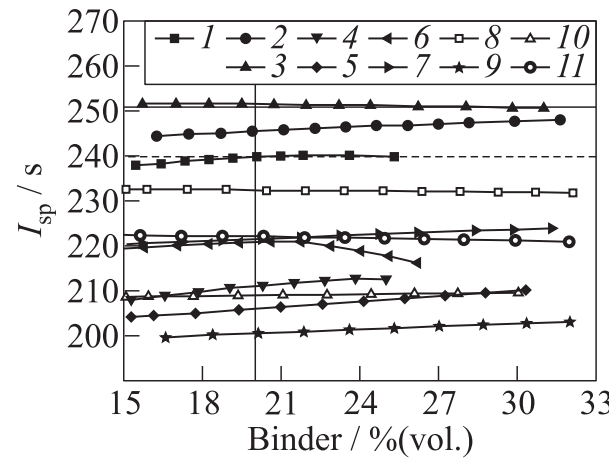

(a)

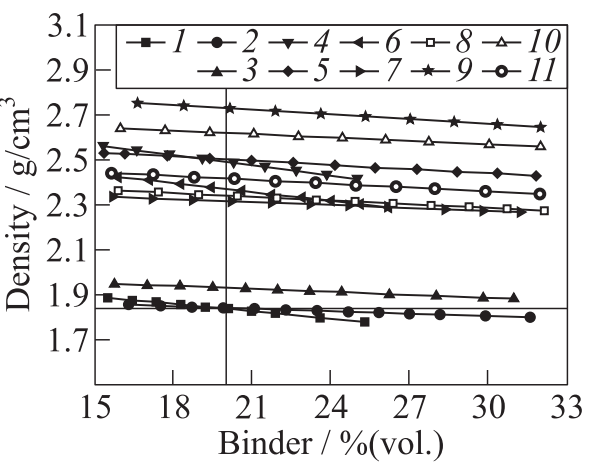

(b)

Figure 2 Binder mass fraction influence on specific impulse $(a)$ and density $(b)$ : 1 - basic; $2-16 \% \mathrm{Al}+\mathrm{AB}+\mathrm{ADN} ; 3-18 \% \mathrm{Al}+\mathrm{AB}+\mathrm{HMX} ; 4-43 \% \mathrm{Zr}$ $+\mathrm{HCB}+\mathrm{AP} ; 5-37 \% \mathrm{Zr}+\mathrm{AB}+\mathrm{AP} ; 6-43 \% \mathrm{Zr}+\mathrm{HCB}+\mathrm{ADN} ; 7-34 \% \mathrm{Zr}$ $+\mathrm{AB}+\mathrm{ADN} ; 8-31 \% \mathrm{Zr}+\mathrm{AB}+\mathrm{HMX} ; 9-49 \% \mathrm{ZrH}_{2}+\mathrm{AB}+\mathrm{AP} ; 10-$ $49 \% \mathrm{ZrH}_{2}+\mathrm{AB}+\mathrm{ADN}$; and $11-37 \% \mathrm{ZrH}_{2}+\mathrm{AB}+\mathrm{HMX}$ 
low and density holds the main role. At high $F$, ballistic effectiveness is higher in case of low density but high $I_{\mathrm{sp}}$ (Al-based formulations).

The compositions that show (always) the higher $I_{\text {ef }}$ are the ones with average properties: not too low $I_{\mathrm{sp}}$ and not too high density. Obviously, because binder density is very low, the resulting composition density is the lower, the bigger is the binder content. The compositions containing HCB are less dense than the same compositions with $\mathrm{AB}$ and, moreover, HCB-based propellants density are affected by binder growth more than AB-based compositions. So, the lower is the binder density, the bigger is the lost, when binder increases.

\subsubsection{Temperature}

The influence of binder mass fraction on flame temperature $T_{c}$ is illustrated in Fig. 3. Formulations containing $\mathrm{Al}$ and $\mathrm{AB}$ have too high $T_{c}$ (about 3800 $4000 \mathrm{~K}$ ) if metal percentage is higher than $20 \%$. Only compositions containing $\mathrm{AB}+\mathrm{HMX}$ have acceptable $T_{c}(3500-3700 \mathrm{~K}$, decreasing if $\mathrm{Al}$ content increases). $\mathrm{Al}+\mathrm{HCB}$ shows $T_{c}$ about $3500-3700 \mathrm{~K}$ but $I_{\mathrm{ef}}$ is too low; if the oxidizer is HMX, $T_{c}(2650-2750 \mathrm{~K})$ is quite too low.

As known, Zr-based formulations have higher temperature than the Al-based ones; especially the ones with $\mathrm{AB}$ as binder have too high $T_{c}$ at high $\mathrm{Zr}$ percentage (the higher is the oxidizer $\alpha$ value, the higher are $I_{\text {ef }}$ and $T_{c}$, too); so, AP, ADN,

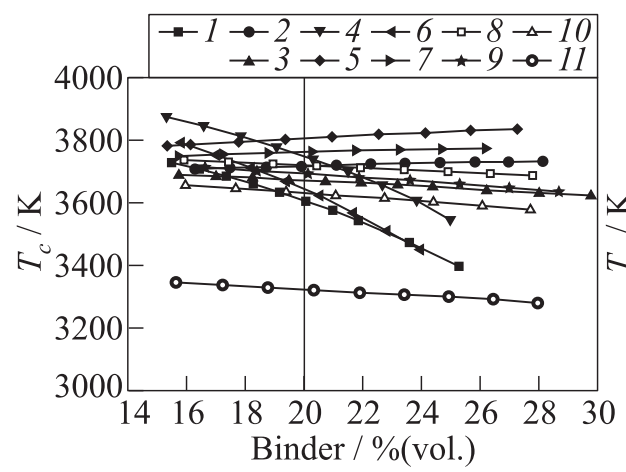

(a)

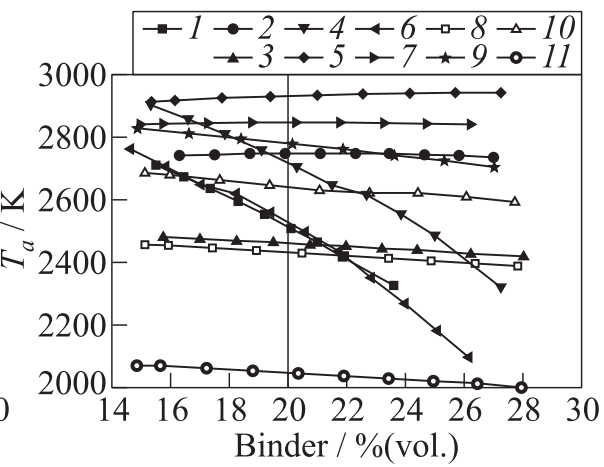

(b)

Figure 3 Binder mass fraction influence on temperatures $T_{c}(a)$ and $T_{a}(b): 1-$ basic; $2-16 \% \mathrm{Al}+\mathrm{AB}+\mathrm{ADN} ; 3-18 \% \mathrm{Al}+\mathrm{AB}+\mathrm{HMX} ; 4-43 \% \mathrm{Zr}+\mathrm{HCB}+\mathrm{AP}$; $5-37 \% \mathrm{Zr}+\mathrm{AB}+\mathrm{AP} ; 6-43 \% \mathrm{Zr}+\mathrm{HCB}+\mathrm{ADN} ; 7-34 \% \mathrm{Zr}+\mathrm{AB}+\mathrm{ADN} ; 8-$ $31 \% \mathrm{Zr}+\mathrm{AB}+\mathrm{HMX} ; 9-49 \% \mathrm{ZrH}_{2}+\mathrm{AB}+\mathrm{AP} ; 10-49 \% \mathrm{ZrH}_{2}+\mathrm{AB}+\mathrm{ADN} ;$ and $11-37 \% \mathrm{ZrH}_{2}+\mathrm{AB}+\mathrm{HMX}$ 
and HMX can be used in formulations with maximum, respectively, 37, 34, and $31 \%$ (vol.) of $\mathrm{Zr}$ (curves 5, 7, and 8, respectively). In compositions containing $\mathrm{Zr}$ with $\mathrm{HCB}$ and $\mathrm{HMX}, T_{c}$ is too low and the results are not good, but, because $T_{c}$ increases if $\alpha$ becomes bigger, if the oxidizer is $\mathrm{ADN}$ or $\mathrm{AP}, T_{c}$ is allowable (3300-3700 K); even if at low binder volume percentages is higher than $3800 \mathrm{~K}$, increasing binder percentage up to $26 \%$ (vol.), $T_{c}$ decreases in $250-300 \mathrm{~K}$ and becomes acceptable.

In compositions with $\mathrm{ZrH}_{2}$ (curves 6 and 9 ), $T_{c}$ is considerably lower than with $\mathrm{Zr}$, because of lower enthalpy of formation and content of hydrogen. In formulations with $\mathrm{HCB}$ and $\mathrm{HMX}, T_{c}$ is too low $(2100-2600 \mathrm{~K})$. If $\mathrm{AB}$ and HMX are used, $T_{c}$ is between 3200 and $3700 \mathrm{~K}$. It has to be remarked that in formulations with $\mathrm{AB}$, increasing binder percentage, temperature does not change, and in compositions with $\mathrm{HCB}$ as binder, $T_{c}$ decreases considerably, if binder increases. The temperatures are higher in AB-based formulations because of its enthalpy of formation.

If $\mathrm{ZrH}_{2}$ is used instead of $\mathrm{Zr}, T_{c}$ decreases, and, increasing metal content, it does not grow up too much (so, metal percentage can be increased more). Moreover, increasing binder, temperature decreases or, at least, it is the same that the one at minimum binder content.

All the chosen formulations have $T_{c}$ in the range $3500-3800 \mathrm{~K}$, except for $\mathrm{Zr}+\mathrm{AB}+\mathrm{AP}$ (curve 5), which has a higher $T_{c}$ (from 3800 up to $3850 \mathrm{~K}$ if binder increases up to $28-30 \%$ (vol.)) and $\mathrm{ZrH}_{2}+\mathrm{AB}+\mathrm{HMX}$ (curve 11) that shows the lowest one (from 3350 to $3300 \mathrm{~K}$, if $\mathrm{AB}$ increases up to $26 \%$ (vol.)).

When creating new composite solid propellants based on $\mathrm{Zr}$ or $\mathrm{ZrH}_{2}$ instead of $\mathrm{Al}$, a choice is given - to create compositions either with maximum value of $I_{\text {ef }}$ (in this case, it is necessary to use binder in minimum acceptable volume percentage that complicates the process of propellant production and degrades the physical-mechanical properties of the propellant) or with a bigger volume percentage of binder. The second way gives compositions with effectiveness not so high as at $20 \%$ (vol.) of binder, but with better physical-mechanical properties.

So, for every propulsive mission, one can choose the binder volume percentage that would be optimum: sometimes, we will sacrifice a bit $I_{\text {ef }}$ to account for better physical-mechanical properties, sometimes vice versa.

\section{CONCLUDING REMARKS}

The replacement of aluminum for zirconium or zirconium hydride increases specific impulse and allows binder to grow up to $28-30 \%$ (vol.), if $F=V / M_{\text {fin }}$ (propellant volume / final vehicle mass) is lower than $1 \mathrm{l} / \mathrm{kg}$. Increasing $V / M_{\text {fin }}$, it is the oxidizer nature that influences effectiveness more than metal does and 
effectiveness decreases more and more with increasing the $\alpha$ value of the oxidizer.

In comparison with HCB-based formulations, the same composition, containing an $\mathrm{AB}$, achieves higher ballistic effectiveness and binder portion can be increased up to $30 \%$ (vol.) (and also, in compositions containing $\mathrm{HCB}$, density decreases quickly if binder percentage is increased and that makes effectiveness falling).

Maximum ballistic effectiveness in compositions containing $\mathrm{Zr}$ or $\mathrm{ZrH}_{2}$ is generally achieved when metal percentage is about $37-46 \%$ (vol.), much higher than optimum $\mathrm{Al}$ content (18-22\%(vol.)). High metallic formulations are soon penalized if binder percentage increases and, also, $T_{c}$ is too high.

Binder fraction can be increased more (up to $30 \%$ (vol.)) and without effectiveness falls in compositions containing $\mathrm{Zr}$ or $\mathrm{ZrH}_{2}, \mathrm{AB}$ and low $\alpha$ oxidizer. Increasing $V / M_{\text {fin }}$, binder growth is as penalizing as higher is oxidizer $\alpha$.

For each task, it is possible to choose the binder volume percentage that would be optimal: sometimes $I_{\text {ef }}$ can be preferred to physical-mechanical properties, sometimes, vice versa, increasing binder content, $I_{\mathrm{ef}}$ can be sacrificed in behalf of physical-mechanical properties.

\section{ACKNOWLEDGMENTS}

Support by Institute of Problems of Chemical Physics, Russian Academy of Science, and EINSTEIN cooperation network is gratefully acknowledged.

\section{REFERENCES}

1. DeLuca, L. T. 1999. Problemi energetici in propulsione aerospaziale. Milan, Italy: SPLab, Dipartimento di Ingegneria Aerospaziale, Politecnico di Milano.

2. Lempert, D. B., G. Nechiporenko, and G. Manelis. 2010. The main tasks in solid composite propellants performances improving. 13th Seminar (International) "New trends in research of energetic materials." Pardubice, Czech. Rep. 1:11-20.

3. Lempert, D. B., G. Manelis, and G. Nechiporenko. 2009. Superdense Zr-containing propellants with density higher than $2.1 \mathrm{~kg} / \mathrm{l}$. XX AIDAA Congress. Milan, Italy.

4. Alekseev, A.P., D. B. Lempert, G. G. Nemtsev, and G. N. Nechiporenko. 2011. Combustion of zirconium containing model compositions of solid propellant. Russ. J. Phys. Chem. B 5(6):997-99.

5. Trusov, B. G. 2002. Program system Terra for simulation phase and chemical equilibrium. 14th Symposium (International) on Chemical Thermodynamics Proceedings. St.-Petersburg. 483. 
6. Lempert, D. B., G. P. Dolganova, H. N. Nechiporenko, and L. N. Stesik. 1997. Dependence of optimized formulations specific impulse upon nature of metal and oxidizer. Russ. J. Chem. Phys. 16(9):91-100.

7. Lempert, D. B., G. N. Nechiporenko, and G.P. Dolganova. 1998. Regularities between formulation, formation enthalpy and specific impulse for energetically optimized solid composite propellants. Russ. J. Chem. Phys. 17(7):7-94.

8. Nechiporenko, G. N., and D.B. Lempert. 1998. An analysis of energy potentialities of composite solid propellants containing beryllium or beryllium hydride as an energetic component. Chem. Phys. Rep. 17(10):1927-47. 